[Berliner Entomol. Zeitschrift Bd. XLVIII, Jabrgang 1903.] 215

\title{
Verzeichnis der von Herrn Richard Haensch in Ecuador gesammelten Ruteliden (Coleoptera lamellicornia).
}

Von Dr. Friedr. Ohaus, Hamburg.

(Mit Abbildung.)

Unter den sudamerikanischen Ländern, die durch die Grossartigkeit ibrer Natur, durch den Reichtum ihrer Tier- und Pflanzenwelt das Interesse der Reisenden und Naturforscher erregen, steht Ecuador in erster Reihe, und gross ist daher die Zahl der Geographen, die sich bemuhten, die gewaltigen Bergketten der Anden zu kartographieren, ihre himmelanstrebenden Spitzen zu ersteigen und zu messen, wie auch der Botaniker und Zoologen, die durch den schier unermesslichen Formenreichtum der dortigen Flora und Fauna angezogen wurden. Nicht zum wenigsten sind es die Insekten, die durch Farbenpracht und eigentümliche Körperformen dem Reisenden auffallen und daher ist auch die Anzabl der aus Ecuador beschriebenen Arten - im Verhältnis zur Grösse des Landes - eine recht grosse. Unter den Reisenden, die auch der Käferwelt Ecuador's ihre Aufmerksamkeit widmeten, nenne ich den Geologen Stübel, dessen Ausbeute von Kirsch in dieser Zeitschrift beschrieben wurde, den Botaniker Wallis, der von 1860 ab Jahre lang Ecuador, Columbien und den Oberlauf des Amazonas bereiste und nebenbei eine grosse Zahl neuer Käfer entdeckte, die jedoch vielfach noch der Beschreibung harren. Auch der berühmte Bergsteiger Whymper, bekannt durch seine zweimalige Besteigung des Chimborazo, brachte eine reiche Käferausbeute mit, die von $\mathrm{H}$. W. Bates in einem besonderen Anhang zur Whymperschen Reisebeschreibung bearbeitet wurde. Ein anderer englischer Reisender, Fr. Rosenberg, der Ende der 90er Jahre das sudwestliche Columbien bereiste, besuchte auch den nordwestlichen Teil von Fcuador und seine Ausbeute ist besonders wertvoll durch die genauen Angaben uber Fundorte und Erscheinungszeit der von ihm 
gesammelten Käfer. Vom März 1899 an bis April 1900 bereiste Herr Richard Haensch aus Berlin verschiedene Teile von Ecuador und wenn auch sein Studium in erster Linie den Lepidopteren gewidmet war, vernachlässigte er doch die übrigen Insektenordnungen nicht und brachte besonders von Käfern eine reiche Ausbeute mit, die neben vorzüglicher Erhaltung durch sorgfültige Notizen über Ort und Zeit des Fanges einen der werthvollsten Beiträge zur Käferfauna von Ecuador liefert. Durch das liebenswurdige Entgegenkommen der Herren Prof. Kolbe vom königl. zoologischen Museum und Hauptmann Moser in Berlin, die die Mehrzahl der von Herrn Haensch gesammelten Käfer erwarben, wurde es mir ermöglicht, die Ruteliden dieser' Sammelausbeute $z u$ studieren und sie im Zusammenhang zu besprechen.

1. Anomala undulata Melsh.* Archidona. Die vorliegenden Stücke bilden gewissermaassen ein Bindeglied zwischen der var. variegata Latr. und der var. peruviensis Guérin. Von der ersteren haben sie das metallische, schmal gelb gerandete Halsschild, von der letzteren die höher gewölbte Körperform und die breiten dunklen Querbinden auf den Deckflügeln; nur bei wenigen sind diese Querbinden in einzelne Flecken aufgelöst, wic dies bei der variegata gewöhnlich der Fall ist; Stücke mit dunkelbraunem Thorax (var. notata Fr) liegen nicht vor.

2. A. popayana Ohs. Balzapamba. Als ich diese Art beschrieb (Stettin. E. Z. 1897 p. 405), kannte ich nur einzelne Stucke aus der Sierra de Popayan im südl. Columbieri. Inzwischen erhielt ich solche von Cachabi, nicht weit von Balzapamba, wie auch vom Rio Dagua (Rosenberg) und von der pacifischen Kuste Costa-Rica's.

3. A. balzapambae Obs. (Stettin. E. Z. 1897 p. 408) bei Balzapamba in grosser Anzahl gesammelt. Die Fundortangabe Banos bei einem einzelnen Stäck im Berliner Museum dürfte wohl auf einem Irrthum beim Etikettieren beruhen.

4. A. testaceipennis Blanch. (= e'ostaricce Bates) Balzapamba, Banos. Auch diese Art gehört zu den weitverbreiteten Arten; sie findet sich von Costa-Rica bis Peru, uberschreitet hier die Anden und dringt durch Bolivien studlich bis nach Paraguay vor.

*) vide Stettin. E. Z. 1902 p. 9. 
5. A. cicatricosa Perty. Archidona.

6 A. aequatorialis Ohs. Banos.

7. A. marginata Fabr.*) Balzapamba, gehört zu den in der neuen Welt am weitesten verbreiteten Arten. Fast alle bei Balzapamba gesammelten Exemplare sind dunkel erzbraun gefärbt, nur wenige haben hellgelbe Deckflügel, wie sie bei den Stücken aus Centralamerika und im Amazonasgebiet die Regel bilden.

8. A. puncticollis Kirsch, bei Banos, Santa Inez und Baiza in grosser Anzahl gesammelt.

9. Strigoderma sulcipennis Burm. ist vom nördlichen Mexico bis Bolivien verbreitet und in Grösse, Färbung und Sculptur ungemein variabel. Ein $\sigma^{*}$ aus Sta. Inez ist glänzend schwarqbraun, Kopf und Halsschild fein grün gesäumt, die Deckflügel braungelb, die Naht und die gewölbten Rippen zwischen Schulter und Seitenrand schwarzbraun, die Unterseite schwach grun schimmernd, die Hinterschenkel hellgelb mit stärkerem Erzschimmer. Ein 우 aus Archidona ist glänzend schwarz, die feinen Furchen auf den Deckflügeln in Grunde braungelb, die Deckflügelnaht grün.

10. Str. Haenschi Ohs. (Stettin. E. Z. 1902 p. 53). Diese durch ganz glatte, furchenlose Deckfligel ausgezeichnete Art wurde bei Sta. Inez in grosser Anzahl gesammelt.

Unter den vielen Gattungen oder Gruppen von Gattungen, aus denen sich die zweite Unterabteilung der Ruteliden, die echten Ruteliden im Sinne Burmeisters und Lacordaires, zusammensetzt, ist die der Lagochilen eine der am besten charakterisirten. Oberlippe und Kopfschild sind fest miteinander verschmolzen und durch eine tiefe mittlere Einkerbung bis nahe zur Stirnnaht gespalten - zwei Merkmale, die sich bei keiner anderen Rutelide wiederfinden. Sodann zeigt bei ihnen die a ussere Lade oder der Helm des Unterkiefers die Eigenthümlichkeit, dass er nur zwei Zähne oder Zahnreihen trägt, nicht drei, wie die ïbrigen Ruteliden. Die sonst vorhandene dritte oder basale Zahnreihe wird bei den Lagochilen dadurch ersetzt, dass der obere Rand dor in neren Lade als breiter scharfer Zahn vorspringt.

In dem Berichit über die wissenschaftlichen Ergebnisse meiner Reise nach Brasilien (Stettin. E. Z. 1899/1900) habe ich auch die Beobachtung mitgeteilt, dass gewisse Lagochile-Arten neben der

*) vide Stettin, E. Z. 1902 p. 34. 
gewöhnlichen Nahrung, Blättern und Blttthen, auch Frtachte fressen, indem sie sich durch deren aussere Schale mit Hilfe der umgebogenen Oberkieferspitzen und der Vorderschienen hindurchzwängen und das weiche Fleisch im Innern verzehren (Bananen, Jacá, Mamao u. s. w.). Untersucht man nun die Mundteile der Lagochilen, so findet man, dass diese der jeweiligen Nahrung entsprechend gebaut sind. Bei den Arten, die ausschliesslich oder hauptsächlich Blätter und Blüthen fressen, befindet sich an der äusseren Lade des Unterkiefers ein relativ schmaler, spitzer Zahn an der Spitze und darunter ein fast ebenso grosser spitzer Zahn; auch der Vorsprung der inneren Lade hat die Form eines schmalen spitzen Zahnes und der basale Mahlzahu der Oberkiefer ist relativ gross. In dem Maasse nun, als ein Ucbergang zur Früchtenahrung stattfindet, wird der basale Mahlzahn kleiner, der apicale Zahn am Unterkieferhelm breiter, seine Spitze runder, seine dorsale Seite gewölbt, die ventrale löffelartig ausgehöhlt. Gleichzeitig wird der untere Zahn des Helms oder der äusseren Lade immer kleiner, um schliesslich bei einigen Arten ganz $\mathrm{zu}$ verschwinden, während der vorspringende Vorderrand der inneren Lade sich verbreitert und schliesslich auf seiner ventralen. Seite ebenso wie der apicale Zahn der äusseren Lade die Form eines Löffels annimmt.

$\mathrm{Zu}$ den Arten, die nach dem Bau ihrer Mundteile wenigstens teilweise Früchtefresser geworden sind, gehört auch Lagochile brunnipes Oliv. resp. der Complex von Arten, der bis jetzt noch unter diesem Namen zusammengefasst wird - eine genauere Untersuchung zeigt uns nemlich, dass mindestens vier verschiedene Arten diesen Namen in den Sammlungen fübren. Gemeinsam ist ihnen eine ther dem Halsschild hochgewölbte, nach jinten mehr abgeflachte Körperform; ihre Oberseite ist glänzend schwarzbraun (bei unausgefärbten Stäcken melır oder weniger rotbraun), der Seitenrand des Halsschildes, die ganze Unterseite, die Beine und die Afterdecke sind gelb, bei einigen Arten sind Afterdecke und Aussenseite der Schienen wie auch die Tarsen schwarzbraun. Die Epimeren der Mittelbrust sind stets von oben sichtbar und - als Teile der Unterseite - stets gelb gefärbt. Die secundären Geschlechtsunterschiede finden sich an den Mundteilen, am letzten Hinterleibsring und an den Beinen. Die Ventralplatte des Aftersegmentes trägt parallel dem Hinterrand eine Reihe zusammenfliessender borstentragender Punkte, die beim $\sigma^{*}$ vor der Afteröffnung in weitem Bogen nach vorn geschwungen ist, beim $ᄋ$ auch vor der Afteröffnung dem Hinterrand parallel läuft (fig. 1,2); die Parthie zwischen der Afteröffnung und diesem Bogen der borstentragenden Punktreihe ist beim $\sigma^{\prime}$ sehr dünn und weich, und legt sich beim Austritt des Forceps faltig zusammen. 
An den Vorderschienen ist der basale Zahn beim $\sigma$ klein, zuweilen kaum angedeutet, beim $ᄋ$ ist er stets kräftig ausgebildet. An den Vordertarsen ist beim $\sigma^{\prime}$ die iunere, an den Mitteltarsen die äussere Klaue verdickt und fein gespalten, die Spaltung jedoch an den Mittelfussen so gering, dass das abgespaltene Zähnchen oder sein Ersatz, die abstehende Borste meist abgebrochen ist und die Klauen daher einfach erscheinen; die Hinterklauen sind stets einfach. Beim 우 sind dagegen die Vorderklauen stets einfach, an den Mittel- und Hinterfüssen ist die äussere Klaue tief gabelig geteilt. An den Oberkiefern ist der Aussenrand beim $\sigma^{7}$ entweder ganz gerade (fig. 13.) oder nur schwach gebogen (fig. 3,17.), beim $\&$ dagegen tief gekerbt (fig. 4.) sodass neben dem Spitzenzahn hier noch ein kräftiger Seitenrahn steht; beide nach oben umgebogen (fig. 5.). Die kräftigere Bezahnung der Oberkiefer und Vorderschienen bat das 우 nöthig, um in das Holz abgestorbener Bäume eindringen und da seine Eier áblegen zu können. Dass die Lagochile-Arten, deren Biologie ich in Brasilien studieren konnte, ihre Eier in abgestorbenen Aesten nicht in Strünken oder auf der Erde liegenden Stämmen wilder Feigenbäume ablegen, wie dies die Macraspis-Arten tun, möchte ich hier kurz erwăhnen.

Ein Merkmal ist ferner der brunnipes-Gruppe eigentumlich, durch das sie sich von den ubrigen Arten der Gattung unterscheidet, nemlich ein Schrillapparat, ahnlich dem von mir bei Macraspis gefundenen. Während jedoch bei Macraspis die Schrillleisten einerseits die ganzen Seiten der Bauchringe bedecken, andererseits anf der Dorsalseite der Hinterschenkel beim Knie in eine erhabene, fein quergeriffelte Leiste zusammengezogen sind, sind sie umgekehrt bei Lagochile an den Seiten der Bauchringe beschränkt auf ein halbovales Feld zwischen Vorderrand und borstentragender Punktreihe, das gewöhnlich sich durch dunkle Färbung von den gelben oder rotgelben Bauchringen abbebt, während die entsprechenden Schrilleisten auf der Dorsalseite der Hinterschenkel beim Knie in ihrer Ausdehnung nicht scharf begrenzt sind.

Die zur brunnipes-Gruppe gehörigen Arten lassen sich nach folgendem Schema auseinander halten.

A. Der Vorderrand der Unterlippe bildet eine gerade Linie oder ist in ganz schwachen Bogen nach hinten geschwungen. Der basale Zahn an der äusseren Lade des Unterkiefers ist relativ klein, der vorspringende Zabn der inneren Lade dagegen relativ gross. Die Oberseite ist glänzend schwarzbraun, der Rand des Kopfschildes und Seitenrand des Halsschildes - hier ist die gelbe Fărbung nicht durch die Scitenfurche begrenzt, sondern greift weiter nach der 
Mitte hin auf den Thorax ủber - wie auch die Dorsalseite von Propygidium und Pygidium sind stets hellgelb, ebenso ist die ganze Unterseite und die Fühler und Beine, mit Ausnahme der Zähne der Vorderschienen und eines kleinen schwarzen Fleckchens bei den Knieen gelb Die Seitenrandfurche am Halsschild reicht bis zur Hinterecke, biegt hier um und setzt sich gewöhnlich noch eine Strecke am Hinterrand fort. Die Aussenseite der Mittel- und Hinterschienen zwischen der oberen und unteren Stachelreihe ist glatt, glänzend. Der: Mesosternalfortsatz ist gerade nach vorn gerichtet, seine Spitze schwach nach oben umgebogen.

a. Kleinere, relativ schlanke und hoch gewölbte Art; die Stirn ist bei den sejtlichen Resten der Stirnnaht tnd bei den Augen dicht aber fein punktirt; der Scheitel, die Mitte des Thorax und das Schildchen sind glänzend poliert, punktfrei; die Seiten des Thorax und die Deckfluggel sind mit sehr feinen, nur bei starker Vergrösserung sichtbaren Pünktchen bedeckt. Das Propygidium ist mit Ausnahme der Seiten matt, weitläufig fein punktiert; das Pygidium gewölbt, beim $ᄋ$ stärker als bejm $\sigma$, glänzend, dicht bedeckt mit feinen Nadelstrichen, die auf der Scheibe ganz flash, an den. Seiten und bei der Spitze vereinzelt etwas tiefer eingerissen sind.

Länge 21-22, Schulterbreite $11 \frac{1}{2} \mathrm{~mm}$. . L. brunnipes Oliv.

Ich besitze Stücke aus Oayenne, die ich mit der Type im Pariser Museum verglichen habe und aus Surinam, die Herr Michaelis ron Mai bis September an Bananen erbeutete, welche er zum Ködern von Schmetterlingen aushängte.

b. Grössere, relativ breitere und flachere Art. Kopfschild, Stirn und Hinterhaupt sind kräftig und dicht, vielfach zusammenfliessend punktiert, nur der Scheitel ist feiner und weitläufiger punktiert, daher auch glänzender... Das Halsschild ist an den Seiten dicht und kräftig, auf der Scheibe weitläufig und fein punktiert, ebenso das Schildchen, die Deckfluggel jedoch sind uberall dicht mit feinen Pünktchen bedeckt. Das Propygidium ist wie bei der brunnipes mit Ausnahme der Seiten matt, aber kräftiger punktiert; das Pygidium ist flacher als bei der eben genannten Art, aber erheblich gröber nadelrissig, die Nadelrisse an den Seiten und bei der Spitze tief eingerissen. Wegen der Unterschiede in der Form der Mundteile und des Forceps siehe Fig. 3-10 resp. 30-33.

ơ. L. $23 \frac{1}{2}$, Br. $13 \mathrm{~mm}$. Ecuador, Sara-yacu? Janson.

오. L. 23, Br. $13 \mathrm{~mm}$. Ecuador, Napo (Haensch).

L. solimoünsis n. sp.

B. Der Vorderrand der Unterlippe ist in der Mitte fein gekerbt oder breiter ausgeschnitten. Am Unterkiefer ist der basale Zahn der äusseren Lade relativ gross und breit, zuweilen in der 
Mitte eingekerbt, sodass die Ecken als spitze Zähne vorspringen; die zahnartig vorspringende Vorderkante der inneren Lade ist relativ klein und spitz, kürzer als der basale Zahn der äusseren Lade. Auf der Oberseite ist auch Propygidium und Pygidium ganz oder zum grösseren Teil schwarz, der Seitenrand des Thorax ist gelb, doch geht die gelbe Färbung nicht über die Seitenrandfurche nach innen hinaus; die Unterseite ist gewöhnlich rotgelb, die Aussenseite der Schienen und die Tarsen schwarz, ebenso die Bauchringe an den Seiten entsprechend der Auslehnung der Schrillleisten. Bei unausgefärbten Stücken, die daran kenntlich sind, dnss die Ränder von Halsschild. Schildchen und Deckftügeln dunkler gefärbt sind als deren Mitte, sind zuweilen Propygidium und Pygidium rotgelb, dann ist jedoch die Aussenseite der Schienen stets schwarz. Die Seitenrandfurche des Halsschildes reicht bis zur Hinterecke oder nur bis zur Mitte des Seitenrandes; die Aussenseite der Mittel- und Hinterschienen zwischen oberer und unterer Stachelreihe ist nadelrissig, wenig glänzend. Der Mesosternalfortsatz ist mehr in kurzem Bogen nach oben gekrümmt.

a. Gross, nach hinten stark abgeflacht, oben glänzend schwarz, der schmale Seitenrand des Halsschildes, das ganze Propygidium und die Spitze des Pygidiums rotgelb; die Unterseite ist rotgelb, die Aussenseite der Schienen und die Tarsen, sowie die mit Schrilleisten bedeckten Seiten der Bauchringe schwarzbraun. Kopf, Halsschild, Schildchen und Deckflügel sind glänzend poliert und mit ganz feinen, nur bei starker Vergrössernng sichtbaren Punktchen weitlänfig überstreut. Die Seitenrandfurche reicht von den Vorderecken nur bis zur Mitte des Halsschildes: Das Propygidium ist glänzend, weitläufig, aber ziemlich kräftig, punktiert. Das Pygidium ist flach, in der Mitte seicht eingedrückt, beim $\sigma$ etwas stärker als beim $\%$, vorn und in der Mitte weitläufig und ganz seicht nadelrissig, an den Seiten und bei der Spitze sind die Nadelrisse dicht, furchenartig vertieft und mit langen rotgelben Borsten besetzt. Die Mundteile sind kraftig gebaut und offenbar zur Bewăltigung grobcr Nahrung eingerichtet, der Oberkiefer auch beim $\sigma$ an der Seite seicht gekerbt, die Einkerbung in der Mitte des Vorderrandes der Unterlippe gewöhulich schwach und durch dichte rotbraune Borsten verdeckt. Der Schrillapparat ist bei dieser Art am stärksten ausgeprägt. Fig. 11, 12.

б. L. $27, \mathrm{Br} .14^{1 / 2}$. 우. L. $25 \mathrm{Br} .14^{1 / 2} \mathrm{~mm}$.

L. panamensis $\mathrm{n} . \mathrm{sp}$.

Es liegen mir $2 \sigma, 3$ 우 von Panama, V. d. Chiriqui, vor, die ich von D. Staudinger erhielt. Die Art ist durch ihre Grösse und die über dem Halsschild hochgewölbte, nach hinten stark abfallende Körperform, durch das abgeflachte schwarze Pygidium mit gelber Spitze und die verkürte Seitenfurche des Thorax leicht kenntlich. 
b. Etwas kleiner, gleichmåssig gewölbt, der Kopf nur bei den Augen fein runzelig punktiert, sonst glänzend poliert, glatt, ebenso Halsschild, Schildchen und Deckflugel. Die Seitenrandfurche des Thorax reicht stets bis zur Hinterecke. Das Propygidium ist in der Mitte weitläufig, an den Seiten dicht mit nach hinten offenen Punkten bedeckt; die Afterdecke ist beim of gleichmässig hochgewölbt, überall dicht nadelrissig, seidenartig glänzend, bei $\sigma^{7}$ gewöhnlich etwas flacher, zuweilen in der Mitte der Länge nach erhaben und nach beiden Seiten hin leicht abfallend, wie beim 오 dicht nadelrissig. . . . . . . . . . . . . L. sparsa n. sp.

Von den vier Arten der Gruppe ist diese am weitesten verbreitet, von Ephrata in Honduras bis Santos in Brasilien, und nach dem mir vorliegenden Material offenbar im Begtiff, in ihren Hauptverbreitungsgebieten. in den Anden, im Amazonastal und an der Ostlküste Südamerikas selbständige Arten zu bilden. Von zwei Fundstellen, Bahia in Brasilien und San Antonio am Rio Mapiri in Bolivien liegen mir grössere 1ndividuenreihen vor und in beiden Fälen kommt zwar der Mehrzahl der Individuen desselben Fundortes eine Anzahl von gemeinsamen Merkmalen zu, durch die sie sich von den Individuen anderer Herkunft leicht unterscheiden, dazwischen finden sich aber einzelne Stücke, die von der Mehrzahl der Sthucke der betreffenden Localität abweichen und mehr Aehnlichkeit mit Stücken anderer Localităten aufweisen. Diese wie auch die weitere Beobachtung, dass ơ derselben Localität individuelle Verschiedenheiten in der Form des Forceps zeigen, bestimmt mich, diese lokalen Formen nur als geographische Subspecies aufzufassen.

Mejne Stuicke aus Centralamerika, Columbien, Ecuador und vom Amazonas zeigen unter sich gewisse Verschiedenheiten in der Färbung und Forcepsform; ich besitze jedoch zu wenig Material von den einzelnen Fundorten, andererseits sind die Fundortangaben teilweise uugenau, sodass ich nicht sagen kann, ob es auch hier - was ich für sehr wahrscheinlich halte - zur Bildnng von Localformen gekommen ist. Ganz ausgefärbte Stücke sind oben glänzend schwarz. auch Propygidium und Pygidium, nur der Seitenrand des Halsschildes, die Epimeren der Mittelbrust und ein kleines Fleckehen beim letzten Stigma auf dem Propygidium sind gelb; die Unterseite ist rotgelb, schwarz dagegen die ganzen Schienen und Tarsen, ein Fleck auf den Schenkeln beim Knie, die Seiten der Bauchringe, soweit sie von Schrilleisten bedeckt sind und - von diesen ausgehend - der Vorderrand der Bauchringe, besonders breit auf dem vorletzten Bauchring, sowie die ganze Ventralplatte des Aftersegmentes. Bei helleren Stücken bleibt auf der Oberseite auch der Rand des Kopf- 
schildes und der Hinterrand des Propygidiums, auf der Unterseite die Innenseite zuerst der Vorderschienen, später auch der Mittelund Hinterschienen und die Spitze des Aftersegmentes rotgelb. Noch weniger ausgefärbte Stüclce, die statt der schwarzen oder schwarzbraunen eine rotbaune Färbung entweder der Deckftúgel allein oder der ganzen Oberseite zeigen, nit dunklerer Färbung aller Rander, haben das ganze Propygidium, in einem Falle sogar das Pygidium rotgelb.

Bei den Ruteliden und - soweit meine bisherigen Beobachtungen reichen - bei allen Lamellicorniern, deren 3-4 letzte $\mathrm{Ab}$ dominalstigmen in der Ventralplatte der Bauchringe liegen, zeigt der Käfer, wenn er die Puppenhaut abgestreift hat, die volle spätere Färbung bis auf die Flügel und Bauchringe (den letzten ausgenommen), die schneeweis bleiben. Er erbärtet sofort resp. in 1-2 Tagen, gebraucht aber längere Zeit, selbst in den Tropen 3-4 Monate, bis auch die Flügel und Bauchrìnge ausgefärbt sind. Dieser mangelbaften Farbung der Flugel und Bauchringe entspricht die mangelhafte Ausbildung der Bauchorgane, in erster Linie der Genitalien, und bis diese abgeschlossen, verweilt der Käfer rubig in seiner Puppenwiege, aus der er sich nur kurz vor seinem normalen Erscheinen im Freien durch starke Regengüsse nach langer Trockenheit hervorlocken lässt. Solche unausgefärbte Stücke sind zur Untersuchung des Forceps wenig geeignet, weil dieser meist noch wenig pigmentiert, dunn und darum auch sehr zerbrechlich ist; dagegen sind sie zur Untersuchung der Mundteile besonders geeignet, weil der Käfer diese noch wenig oder gar nicht gebraucht hat und dalier die feinen Zähne und scharfen Kanten, die sich später durch den Gebrauch abnutzen, gut erhalten sind.

Beim $\sigma^{\prime}$ ist der Aussenrand der Oberkiefer wenig oder gar nicht gebùchtet, beim $\&$ dagegen krüftig gekerbt, der Spitzenzah॥ und Seitenzaln breit, scharfkantig und scharf nach oben umgebogen. Am Unterkiefer ist der basale Zahn der äusseren Lade gross und breit, mit scharfen Ecken, die obere (den Kafer in natỉrlicher Lage, d. h. laufend gedacht) zahnartig vorspringend, der zahnartige Vorsprung der inneren Lade ist relativ klein. Es liegen mir Stacke vor aus Ephrata, Honduras, im Febr. 1832 von Ellacombe gesammelt; Columbien, von der Sierra de Popayan und vom Oberlauf des Rio Napo; Ecuador (Baron), wahrscheinlich aus dem Hochgebirge bei Loja, und von Balzapamba (Haensch); vom Amazonas, S. Paulo d'Olivenca (M. de Mathan) und Ega (Bates).

Die $\sigma^{\prime}$ variiren in der Länge von $24 \% \frac{1}{2}-25$ bei einer Schulterbreite von $14-14^{1} / 2 \mathrm{~mm}$, die o von $21-28$, resp. $11 \frac{1 / 2}{2}-14^{1 / 2} \mathrm{~nm}$. 


\section{L. sparsa subspec. subandina.}

Die Stüclre von S. Antonio am Rio Mapiri in Bolivien wie auch einige Stücke aus Callanga in Peru, vom Rio Putomayo und rom Rio Napo (Haensch) haben einen deutlichen Metallglanz auf der Oberseite, bei den dunklen Stücken erzgrün, bei helleren kupfrig. Nie ist das Kopfschild gelb gerandet, sondern einfarbig schwarzbraun oder (bei helleren Stücken) die spitzen Lappen im Ganzen rotbraun. Dagegen ist der Seitenrand des Thorax stets rotgelb und diese Färbung geht häufig wie bei brunnipes etwas über die Seitenrandfurche hinaus. Das Propygidium ist in beiden Geschlechtern schwarzbraun mit schmalem gelbem Hinterrand, nur bei einem unausgefärbten Paar, einen $\sigma$ vom Rio Napo und einem of vom Rio Mapiri, ist es im Ganzen rotgelb. Dns Pygidium ist beim ơ stets rotbraun, beim 우 meist schwarzbraun, nur bei unausgefärbten Stücken rotbraun. Die Unterseite ist rotgelb, bei einigen ist die Aussenseite der Vorder- and Mittelschienen schwarzbraun, die Aussenseite der Hinterschienen stets rotgelb (ausgenommen nur $1 \sigma^{7}$ vom R. Mapiri) mit schwarzen Stacheln; auch ein Fleckchen beim Knie, der Hinterrand der Tarsen und die Klauen sind schwarzbraun. Die Seiten der Bauchringe in der Ausdehnung des Schrillaparates, zuweilen auch ihr Vorderrand, besonders breit auf dem vorletzten Bauchring, sind schwarzbraun. Die Lappen des Kopfschildes und die Stirn bei den seitlichen Resten der Stirnnaht ist beim $\sigma^{\prime}$ spärlich, beim 우 dicht zusammenfliessend punktiert; Scheitel, Halsschild und Schildchen sind ganz glatt, stark glänzend, ebenso die Deckflügel beim $\sigma^{\prime}$ (mit Ausnahme eines $\sigma^{7}$ vom Mapiri), während sie beim, 오 fein aber ziemlich dicht punktiert sind. Bei den hellen Stücken lässt sich deutlich erkennen, dass die Punktierung auf die Zwischenräume zwischen den durch Reihen stärkerer Punkte begrenzten prim. Rippen beschränkt ist. Das Propygidium ist dicht und kräftig punktiert, wenig glänzend, nur der gelbe punktfreie Hinterrand ist glänzend poliert. Die Afterdecke ist dicht und kräftig nadelrissig, seidenartig glänzend, beim $\sigma$ etwas abgeflacht, die Spitze zugerundet, beim ㅇ hochgewölbt, bei den Stücken vom Mapiri. und aus Callanga deutlich zugespitzt, bei einem 오 vom $R$. Putomayo ebenso gerundet wie beim $\sigma$. Der Mesosternalfortsatz ist wagrecht nach vorn gerichtet, seine Spitze sanft nach oben gebogen, wie bei brunnipes und solimoënsis.

Die Kiefer zeigen dieselben Verschiedenheiten wie bei den Stacken von Golumbien und Ecuador, ebenso die Parameren des Forceps (fig. 38). 
Die Länge variirt beim $\sigma$ von $22 \frac{1}{2}-24$, die Breite von $12 \frac{1}{2}$ -13 , beim o von $22^{1 / 2}-26$ resp. $11^{1 / 2}-13^{1 / 2} \mathrm{~mm}$. Ein $Q$ vom $R$. Putomayo erreicht die stattliche Grösse von 28 resp. $15 \mathrm{~mm}$.

\section{I. sparsa subspec. littoralis.}

Hier geht die Ausbreitung der dunklen Färbung am weitesten von allen Arten der Gruppe. Bei dunklen Stücken werden ausser dem Kopfschild auch die Lappen der Oberlippe, die bisher gelb blieben, schwarz, an Halsschild auch der Seitenrand, ferner das ganze Propygidium und Pygidium, sodass bei diesen Stücken auf der Oberseite nur die Epimeren der Mittelbrust noch gelb sind. Auf der Unterseite sind die ganzen Schienen und Tarsen, die Sckenkel beim Knie. Seiten und Vorderrand der Bauchringe und der ganze vorletzte und letzte Bauchring schwarz, der Rest ist gelb. Bei helleren Stücken, auf der Oberseite glänzend kastanienbraun mit schwarzbraunen Rändern, ist oben der Seitenrand des Halsschildes und das Propygidium in grösserer oder geringerer Ausdehnung gelb, unten bleibt selbst bei den hellsten. Stucken die Aussenseite der Schienen und die Tarsen schwarz, während die dunkle Färbung auf den Bauchringen bis auf einen schmalen Streifen am Vorderrand des vorletzten Bauchringes verschwinden kann. Eigentümlich ist clas individuelle Schwanken in der Ausbildung der Seitenrandfurche auf dem Halsschild. Bei der Mehrzahl der Stücke ist sie scharf ausgeprägt bis zur Hinterecke; bei einigen jedoch, $\sigma$ sowobl wie 0 , reicht sie nur bis zur Mitte und von da bis zur Hinterecke stehen einige Punkte. Kopfschild and Stirn sind fein punktiert, bei hellen Stücken weniger als bei dunkeln; Scheitel, Halsschild, Schildchen und Deckflugel sind punktfrei, glänzend poliert. Das Propygidium ist ziemlich dicht punktiert, die Afterdecke dicht quernadelrissig, matt seidenartig glänzend, beim o hochgewölbt, beim $\sigma^{7}$ kaum flacher. Der Oberkiefer zeigt bei allen mir vorliegenden $\sigma^{\prime}$ an der Aussenseite nahe der Spitze eine flache Ausbuchtung, am Innenrand springt die untere Ecke der sonst gerade abgestutzten Spitze zahnartig vor (fig. 17). Der basale Zahn an der äusseren: Lade der Unterkiefer ist durch Einkerbung in zwei Zähne gespalten. (fig. 18). Die Forcepsform ist bei den meisten $\sigma$ konstant, nur bei einem $\sigma^{\prime}$ von Bahia sind die Parameren schlanker (fig : 39).

$\sigma$ L. $23-25 \frac{1}{2}$, Br. $13-13 \frac{1}{2}$, 우 L. $24-24 \frac{1}{2}$, Br. $13 \frac{1}{2} \mathrm{~mm}$.

Es liegen mir Stacke vor aus Ceara, Serra de Baturité, von Herrn E. Gounelle im Januar 1895 gesarnmelt; von Pernambuco (Staudinger); von Bahia, S. Felix und Santos (D. Laske). 
11. Lagochile solimoënsis n. sp. Napo.

12. L. sparsa n. sp. Balzapamba.

13. L. sparsa subspec. subandina Coca.

14. I. chiriquina Bates. Balzapamba. Die Art wurde in Ecuador ausserdem bei Paramba (im März) und am Rio Dagua in Columbien von Rosenberg, am Volcan de Chiriqui, und bei San Carlos in Costa-Rica (Schildt und Burgdorf) gesammelt.

15. L. andicola n. sp. Der vorhergehenden Art zunächst verwandt, gleicht sie in Grösse und Färbung den gelbbraunen Stücken der $L$. bipunctata M. L. aus Espirito Santo, ist oberseits rötlich gelbbraun, Kopf; Halsschild und Schildchen etwas dunkler als die Deckflügel; Kopfschild und Oberlippe, der schmale Seitenrand des Halsschildes und der Deckflugel wie auch der Hinterrand des Propygidiums sind $\mathrm{d}_{\mathrm{x}}$ hell rötlichgelb. Die Unterseite ist hell rötlichgelb, die Aussenseite der Schienen etwas dunkler, der Vorderrand der Bauchringe - zuweilen bis auf einen schmalen gelben Saum am Hinterrand - schwarzbraun. Die Lappen des Kopfschildes sind spitzwinklig mit scharf ausgepräglem Rand, durch ein tiefes Grübchen von der Stirn getrennt, ebenso wie Stirn und Scheitel weitläufig fein punktiert. Die Seiten des Thorax divergiren von der Basis aus bis kurz vor der Mitte, dann laufen sie nach vorn zu stark 7usammen, die Seitenrandfurche reicht von der Vorderecke nur bis zur Mitte, die ganze Oberfläche ist glänzend poliert, punktfrei. Das Schildchen ist wie bei der chiriquina geformt, an der Basis mit schmalem, rötlichgelben Querstreifen, dahinter folgt ein breiter, nach hinten verloschener dunkelbrauner Querstreifen, der im Verein mit den breiten dunklen Seitenstreifen bei der Spitze ein helles Dreieck umschliesst; die Oberfläche ist ebenso glänzend poliert wie das Halsschild. Die Deckftugel sind neben der Schulter eingedrückt und nach hinten erweitert; die Punktreile neben dem Seitenrand ist regelmässig bis zur Hintereckc, die Partie neben der Schulter deutlich punktiert, auch bei der Basis finden sich Reste von Punktreihen. Das Propygidium ist glänzend, weitläufig kräftig punktiert. Das Pygidium ist in beiden Geschlechtern flach mit gerundeter Spitze, beim $\sigma^{7}$ mit einem leichten Längswulst in der Mitte und schwachem Eindruck beiderseits daneben, die Scheibe ziemlich dicht, aber seicht quergestrichelt, die Seiten und die Spitze grob nadelrissig mit abstehenden roten Borsten bekleidet. Die Bauchringe sind glatt mit der gewöhnlichen borstentragenden Punktreihe; Brust und Hinterhüften sind dicht nadelrissig, fuchsrot behaart. Der Mesosternalfortsatz ist wagrecht nach vorn gerichtet, die nicht ver- 
dickte Spitze nur wenig nach oben umgebogen. Vorderschienen 3-zähnig, die beiden oberen Zähne einander genähert, beim 우 alle sehr kräftig, beim ơ die beiden oberen fein und schlank, der basale nur noch als kleine Ecke an der Mitte der Seite angedeutet. Beim $\sigma$ ist an den Vorderfussen das Klauenglied verdiclit, die innere Klaue verbreitert und liräftig gespalten, an Mittel- und Hinterftussen beide Klauen einfach; bei $O$ s sind beide Vorderklauen einfach, an den Mittel- und Hinterfüssen ist die äussere Klaue gespalten. Die Fühlerkeule ist in beiden Geschlechtern gleich lang. Die Mundteile sind gebildet wie bei der chiriquina, die Oberkiefer in beiden Geschlechtern an der Aussenseite neben der Spitze ausgebuchtet (fig. 19) am Unterkieferhelm ist der basale Zahn auf ein kleines Zähnchen an der Basis des grossen, löffelförmig ausgehöhlten Spitzenzahnes reduziert (fig. 20.).

б. L. $18 \frac{1}{2}$, Br. $11 \frac{1}{2}$ : 오. L. 20, Br. $12 \mathrm{~mm}$. Sta. Inéz.

Wir können die neue Art wohl als eine Hochgebirgsform der die niedrigen Vorberge auf der pacifischen Seite bewohnenden chiriquina Bates auffassen, von der sie sich th. A. durch das Fehlen der schwarzen Färbung auf Kopf und Halsschild, das Fehlen des schwarzen Dreiecks auf dem Schildchen und durch Form und Sculptur der Afterdecke unterscheidet. Während diese bei andicola $\sigma$ an der Spitze gerundet und auf der Scheibe, wenn auch seicht, so doch dicht quergestrichelt ist, hat sie bei chiriquina $\sigma$ an der Spitze eine deutliche Einkerbung und ist auf der Scheibe ganz weitlăufig gestrichelt, hăufig sogar ganz glatt. Auch beim $\&$ der chiriquina ist die Sculptur der Afterdecke weitlüufiger und seichter, ihre Spitze mehr zugerundet, als beim $\$$ der andicola. Ferner ist die Form des Forceps beider Arten ganz verschieden (fig. 40, 41). Die Bezahnung der Oberkiefer an der Aussenseite auch beim $\sigma$, die Rückbildung des basalen Zahnes am Unterkieforhelm, dessen Spitzenzahn vergrössert und löffelartig ausgehöhlt ist, sprechen für ausschliessliche oder nahezu ausschliessliche Fruchtenahrung.

16. L. cachectica nov. spec. Wie die vorhergehende zu den Arten der Gattung gehörend, bei denen die Epimeren der Mittelbrust von oben nicht sichtbar sind, steht sie im Habitus und nach der eigenartigen Form des Forceps der L. venezolana $\mathrm{m}$. am nächsten. Oberlippe und Kopfschild sowie ein kleines Fleckcben mitten am Vorderrand der Stirn sind hell rötlichgelb, glanzend poliert, punktfrei; Stirn und Scheitel sind glänzend schwarzbraun, nur bei den Augen mit groben Punkten besetzt, die wie gewöhnlich abstehende rote Borsten tragen. Das Halsschild ist wachsgelb, glanzend, punktfrei; 
die seitliche Randfurche von der Vorderecke nur bis zur Mitte reichend. Das Schildchen ist glänzend wachsgelb mit dunkelbraunen Seitenrändern, ohne Sculptur. Die Deckflugel sind scherbengelb mit helleren Rändern, regelmässig fein gefurcht und in den Furchen punktiert (prim. Punktreiben), das I. oder subsuturale Interstitium und der Schulterbuckel unregelmässig punktiert, die anderen Interstitien punktfrei. Das Propygidium ist hell rötlichgelb, zerstreut punktiert; die Afterdecke glänzend schwarzbraun, dicht quernadelrissig, beim $\sigma^{\prime}$ anf der Scheibe etwas abgeflacht, an den Seiten fuchsrot behaart. Die Unterseite einschliesslich der Fuhler und Beine ist hell rötlichgelb, stark glänzend, die Mitte der Brust und dic Bauchringe - ausgenommen den vorletzten und den Hinterrand des letzten - sind schwarzbraun. Die Bauchringe sind an den Seiten fein runzelig (kein Schrillapparat), die Borsten der gewöhnlichen Reihe borstentragender Punkte an den Seiten dichter stehend. Die Brust ist an den Seiten dicht runzelig und abstehend rotgelb behaart, der Mesosternalfortsatz nach vorn gerichtet, die nach oben umgebogene Spitze schwach verdickt. Die. Vorderschienon sind 3zähnig, der basale beim ơ fast verloschen, der mittlere und apicale einander genähert. Die Spaltung der Klauen beim $\sigma$ und die Form der Mundteile ist wie bei der vorhergehenden Art.

20 sammelte, Herr Haensch, das eine bei Baiza $23 \% \mathrm{~mm}$ lang, $13^{1 / 2}$ breit, das andere bei Sta. Inéz, 201/2 resp. $11^{1 / 2} \mathrm{~mm}$ messend.

Die zunächst verwandte $L$. venezolana $\mathrm{m}$. ist grösser und relativ flacher, die ganze Oberseite gleichmässig rötlicbgelb, Kopf und Kopfschild sowie die grössere vordere Halfte des Halsschildes glanzend schwarz; auf der Unterseite ist nur die Innenseite der Schienen und ein Fleckchen an den Seiten der Bauchringe, sowie Tarsen und Fühler braungelb, alles Uebrige schwarzbraun. Der Forceps ist ähnlich dem der cachectica, die verschmolzenen Parameren aber etwas breiter und an der Spitze mehr ausgebreitet.

17. L. trigona Hrbst. Archidona.

18. Macraspis pantochloris Blanch. Coca.

19. M. melanaria Blanch. Balzapamba und Palmar; von Rosenberg auch bei Cachabi (XI. 96) und Paramba (III. 97) gesammelt.

20. M. chloraspis Cast. Archidona.

21. M. Desmarestii Waterh. Sta. Inéz.

22. M. maculata Burm. Coca. 
Pseudomacraspis, gen. nov. Antichiridarum.

Gelegentlich einer Besprechung der echten Ruteliden der neuen Welt in der Stettin. E. Z. 1898 p. 42 u. f. habe ich aus der Gattung Antichira Esch. alle die Arten, die mit einem Schrillapparat versehen sind, bestehend aus erhabenen Leisten an den Seiten der Bauchringe und einem quergeriffelten Wulst auf der Dorsalseite der Hinterschenkel beim Knie, entfernt und unter dem alten Mac Leay'schen. Namen Macraspis zu einer selbständigen Gattung vereinigt. Weitere Merkmale dieser Gattung sind 1) ein Schildchen, das so lang oder nur wenig kurzer ist, als die Deckflügelnaht; 2) ein Mesosternalfortsatz, der bis zwischen die Vorderhüten reichend entweder wagrecht nach vorn gerichtet (fig. 28) oder schwach nach unten gesenkt, mit der Spitze nach oben umgebogen und an dieser Spitze kolbig verdickt ist (fig. 29); 3) Oberkiefer, die in beidenGeschlechtern am Seitenrand nahe der Spitze tief gekerbt sind (fig 21), so dass neben dem Spitzenzahn ein deutlicher Seitenzahn erscheint, beide mehr oder weniger nach oben umgebogen. In die so charakterisierte Gattung Macraspis kommt nahezu die Hälfte der Arten, die im Munchener Katalog unter dem Gattungsnamen Antichira aufgeführt werden. Unter den bei Antichira verbliebenen Arten - alle ohne Schrillapparat - giebt es nun einige, 4-5, die man auf den ersten Blick für eine Macraspįs halten möchte, da ihr Sehildchen nur wenig kuruer ist als die Decliflugelnaht; aber ihre Oberkiefer sind am Seitenrand ganz glatt ohne Einkerbung oder Seitenzahn (fig. 22), und ihr Mesosternalfortsatz, ebenso gross wie bei Macraspis. ist stärker nach unten gesenkt und die zwischen die Vorderhuften reichende hakenförmig nach oben umgebogene Spitze ist nicht kolbig verdickt (fig. 27). Auch ist ihr Schildchen stets etwas kürzer und schmäler als bei gleich grossen Arten der Gattung Macraspis. Diese vier Merkmale - ein Schildchen, das nur wenig kürzer ist, als die Deckflugelnaht, am Aussenrand ungekerbte Oberkiefer, ein grosser, gebogener, spitzer Mesosternalfortsatz und das Fehlen eines Schrillapparates - unterscheiden die damit ausgestatteten Arten ausreichend von Macraspis wie auch von Antichira und berechtigen zur Aufstellung einer eignen Gattung, für die ich den Namen Pseudomaonaspis wähle. $\mathrm{Zu}$ ihr gehört affinis Cast. (prcisina Burm.), in Guayana und im ganzen Amazonasgebiet bis nach Ecuador und Columbien verbreitet, beryllina Er. von Peru, Chanchamayo sowie zwei neue Arten; nemlich cayennensis $\mathrm{m}$. - der ganze Körper braun, lebhaft violett glänzend, nur die Deckflugel und die Seiten dess Halsschildes hell rötlichgelb (ein $q$ aus Cayenne, $20 \mathrm{~mm}$ lang, 12 breit) - und imitatrix m. - der ganze Körper glänzend schwarz, nur 
die Deckflugel hell robtlichgelb mit 3 dunkleren Langsstreifen (ein 오 vom Rio Cachiyacu bei . Iquitos, $22^{1} / \mathrm{mm}$ lang, 12 breit); vielleicht gehört auch $A$. modesta Waterh. von Cuença in Ecuador in diese neue Gattung. Es ist nun höchst auffallend, dass die zuerst genannten vier Arten je einer Art der Gattung Macraspis, die an denselben Localitäten wie sie selbst vorkommt, in Körperform und Färbung zum Verwechseln ahnlich sieht. So gleicht Pseudomacraspis affinis der Macraspis chrysis, beryllina der peruana m., cayennensis der splendida Fabr. und imitatrix der testaceipennis m. Leider ist uns über die Biologie dieser Arten nichts bekannt; wir wissen nur, dass sie an denselben Orten vorkommen, aber nicht, ob auch $z u$ derselben Jahreszeit, sodass für eine Erklärung dieser Erscheinung, die an bekannte. Verhältnisse bei den Schmetterlingen erinnert, zur Zeit jeder Anhalt fehlt. In einem Vortrag über Mimetismus zwischen verschiedenen Farnilien der Kăfer, gehalten auf der Versammlung Deutscher Naturforscher und Aerzte in Hamburg 1901 (Bericht p. 266) habe ich auch über Mimetismus zwischen Käfern verschiedener Gattungen innerhalb derselben Familie gesprochen und auf folgende Punkte verwiesen, die vielleicht geeignet sind, den Weg zur Erklärung dieser Erscheinung zu zeigen. Die spärlichen Beobachtungen über die Biologie der echten Ruteliden zeigen uns, dass die Arten, die im Larvenstadium gleiche Lebensweise resp. Futterpflanze haben, als ausgebildete Insekten verschiedene Lebensweise resp. Futterpftanze haben. So leben z. B. Macraspis cincta und clavata als Larven einträchtig neben einander in denselben Figueirastrünken (wilde Feigenbäume), als Käfer jedoch frisst die erstere die Blüten von Inga (Mimosaceae), clavata die Blutter einer Melastomacee. Umgekehrt haben die Arten, die als Kâfer dieselbe Futterpflanze aufsuchen, im Larvenzustande verschiedene Futterpflanzen, wie z. B. Macraspis cincta und variabilis, die als Käfer Ingablutten fressen, wovon jedoch die erstere als Larve in abgestorbenen Stämmen wilder Feigenbäume. die letztere in solchen von Melastomaceen lebt. Es wäre nun denkbar, dass die sich so ähnlich sehenden Macraspis und Pseudomacraspis sowohl als Larve wie auch als Käfer dieselbe Futterpflanze hätten; die gleiche Körperform und Färbung wäre dann ein Resultat der gleichen Lebensweise, die wohl Einfluss hat auf die allgemeine Körperform und Färbung, die charakteristischen Gattungsmerkmale jedoch unberïhrt lässt. Erwǎhnen möchte ich noch, dass ähnlich wie bei den Lepidopteren, die Pseudomacraspis viel seltener sind als die Macraspis-Arten, denen sie gleichen. 
23. Psoudomacraspis affinis Cast. Archidona und Napo. Das Verbreitungsgebiet dieser Art erstreckt sich über Guayana, Cayenne und Surinam (Mai bis Sept. von Michaelis gesammelt); Para 'April); Rio Javary, ein rechtseit. Nebenfluss des Amazonas, der bei Teffé mündet; Peru, Yurimaguas; Ecuador, Napo und Archidona (Haensch), Sara-yacu (Buckley); Columbien, Rio Putomayo, Bogotá (Tring Museum) und Cauca-Thal (Weber'sche Sammlung). Es scheint, dass auch diese Art, ähnlich wie Lagochile sparsa, im Begriffe ist, sich in eine Anzahl von lokal beschränkten Formen aufzulösen, doch sind die unterscheidenden Merkmale noch sehr gering und, soweit ich bis jetzt feststellen konnte, auf die mannlichen Geschlechtsmerkmale beschränkt. Bei den Guayanastücken haben die Forcepsparameren an der Spitze ein gerundetes, nach unten umgebogenes Zähnchen, das bei den Parastucken schon kurzer ist and, um so mehr abnehmend, je weiter der Käfer nach Westen vordringt, bei den Stücken vom Oberlauf des Amazonas und aus Columbien schliesslich ganz fehlt (fig. 42, 43.). Ferner haben die Guayanastücke schmale, deutlich 3-zähnige Vorderschienen, die Vordertarsen und die innere Klaue sind relativ schlank (fig. 23, 24.); bei den Stücken vom Ostabhang der Cordilleren und von Columbien : werden die Schienen breiter, der basale Zalun verschwindet, die Vordertarsen und die innere Klaue werden breiter und dicker (fig. 25, 26.). Bei den 오 habe ich entsprechende Unterschiede - Sculptur der Bauchringe - nicht finden können.

24. Antichira jodiella Bates var. nigra m. Balzapamba.

25. A. fulgida Waterh. Archidona und Coca.

26. Hypaspidius crassus Obs. Ein einzelnes $ᄋ$ aus Banos in der Sammlung des Herrn Hauptmann Moser, das in der Grösse und in der Form und Färbung des Thorax viel mehr mit meinem $\sigma^{7}$ aus Frontino (Wallis) ubereinstimmt, als das 우 aus Panama, das ich bei der Beschreibung dieser Art vor mir hatte; vielleicht erweisen sich, wenn erst mehr Stlucke bekannt sind, die Panamastücke als specifisch verschieden von denen aus Fcuador resp. dem stadlichen Columbien.

27. Thyridium punctiventre Waterh. Sta. Inéz.

28. Chlorota terminata Serv. Archidona. Ein einzelnes $ᄋ$ im Berliner Museum. Wie Lagochile sparsa und Pseudomacraspis affinis scheint auch diese Art sich in einzelne Lokalformen auflösen $\mathrm{zu}$ wollen. Es liegen mir Stlicke vor aus Guatemala, vom Volcan de Chiriqui, von der Landenge von Panama, von Bogota und rom Rio Dagua, vom Rio Meta, von Surinam und Cayenne, ron Obidos am Amazonas, von Espirito Santo und S. Paulo in Brasilien. An jeder 
dieser Lokalitäten haben die $\sigma$ ihre besondere Forcepsform und so sehr diese auch bei den $\sigma^{7}$ verschiedener Lokalitäten verschieden ist, bei den $\sigma^{7}$ derselben Localităt bleibt sie stets unverändert: Von einigen Lokalitäten, z. B. Chiriqui, Surinam und Espirito Santo habe ich mehrere Dutzend $\sigma^{\prime}$ untersuchen können und bei ihnen stets dieselbe für die betr. Lokalität typische Forcepsform gefunden, während andererseits die auffallendsten Unterschiede in der Form des Forceps gerade bei $\sigma$ nahe bei einander liegender Lokalitäten sich vorfinden.

29. Chlorota Dohrni Ohs. Banos. In der Stettin. E. Z. 1898 p. 54 beschrieb ich diese Art als Diabasis, eine genauere Untersuchung des Typus generis lässt es mir aber richtiger erscheinen, sie in der zunächst verwandten Gattung Chlorota unterzubringen. Herr Hänsch sammelte sie in grösserer Anzahl, mit Puppen derselben Art zusammen in einem mulmigen Baumstamm und es lässt sich aus diesen Stücken erkennen, dass sie in der Färbung sehr variabel ist. Als Dohrni beschrieb ich die Form, bei welcher Kopf, Halsschild und Schildchen lebhaft erzgrun, die schmalen Seiten des Halsschildes, die Deckflutgel und die Unterseite gelb sind. Ein anderes Stick, o', ist mehr rötlichgelb, der Kopf und die zwei breiten Streifen auf dem Halsschild sind braun mit violetten Schimmer. Als auricollis beschrieb ich grüne Stúcke mit goldglänzendem Halsschild; eine weitere auffallende Varietät ist die var. violacea m., Ober- und Unterseite gleichmässig violett. In der Länge schwanken die mir vorliegenden Stücke von $14-18$, in der Breite von $8-11 \mathrm{~mm}$.

30. Rutela heraldica Perty. Coca.

31. R. lineola L., v. ephippium Fabr. Coca und Aguamo, zwischen Coca und Napo gelegen. Wahrend in Guayana und im östlichen Teil des Amazonasgebietes, etwa bis Manaos, dic dunklen Stucke vorherrschen (surinama L.), findet sich im westlichen 'Teil des Amazonasgebietes fast ausschliesslich die grössere Form mit den gelben Flecken auf den Deckfluggeln (ephippium Fabr.). Im Münchener Katalog ist die $\boldsymbol{R}$. histrio Sahlb, als Varietät zur lineola gestellt. Das ist ein Irrtum. $R$. histrio Sahlb. ist eine selbständige Art, die zwar vielfach an denselben Orten wie $R$. lineola gefunden wird, sich aber durch etwas küzere, gedrungene Körperform und die kräftige Punktierung der Oberseite, bes. des Thorax von dieser leicht unterscheidet; beim $\sigma$ von lineola sind die Trochanteren der Hinterschenkel in eine vorragende Spitze ausgezogen, bei histrio nicht. 
32. R. dimorpha $n$. sp. Balzapamba. Diese Art bildet das auffallendste Beispiel von verschiedener Färbung der beiden Geschlechter unter den echten Ruteliden der neuen Welt und erinnert lebhaft an ăhnliche Falle bei den echtén Ruteliden der alten Welt, den Parastasiiden. Ausser einem 오, das Herr Haensch bei Balzapamba sammelte, besitze ich noch 3 Pärchen aus La Chima, im ersten Semester 1893 von Herrn v. Mathan gesammelt. Die Färbung ist bei allen Sttkcken desselben Geschlechtes dieselbe; beim $\sigma$ ist die Oberseite glänzend schwarz, nur die Seiten des Halsschildes (ausgenommen ein schwarzer Fleck an Stelle des Seitengrübchens), ein dreieckiger Fleck an der Basis des Schildchens und eine grosse Makel, beiden Deckflúgeln gemeinsam, hinter und neben dem Schildchen sind citronengelb oder schwach rötlichgelb; auf. der Unterseite ist der Mesosternalfortsatz und Vorderrand der Hinterbrust, ein Fleck auf dem vorderen und mittleren Hüftring, der ganze hintere Hüftring und ein langer Fleck beim Vorderrand der Hinterschenkel gelb, alles Uebrige ist schwarz. Beim $Q$ ist die ganze Oberseite gelb, nur der Kopf (ausgenommen ein ovaler. gelber Fleck auf dem Scheitel), zwei längliche Flecke auf dem Thorax, die den Vorderrand berthren, alle Ränder des Halsschildes, Schildchens und der Deckfluggel, das ganze Propygidium und zwei kleine Fleckchen am Hinterrand der Afterdecke sind schwarz; die Unterseite ist ebenso gefärbt wie beim $\sigma^{\prime}$. Das Kopfschild ist dicht runzelig punktiert, fein gerandet, in der Mitte tief eingeschnitten, die beiden Zacken beim $\sigma^{7}$ kürzer und mehr zugerun.det, beim \& länger, spitzer und mehr nach oben umgebogen." Die Stirnnat ist in der Mitte durch einen Höcker unterbrochen, die Stirn weitläufig punktiert, der Scheitel hinter dem Stirnhöcker leicht eingedrückt, glänzend glatt. Das Halsschild ist hochgewölbt; lebhaft glänzend, an den Seiten fein gerandet, die grössere vordere Hälfte weitläufig kräftig punktiert, die hintere Hälfte ganz punktfrei. Das . Schildchen ist wie bei den meisten Arten der Gattung geformt, glänzend poliert, punktfrei. Die Deckflugel sind ebenfalls lebhaft glänzend, mit regelmässigen Punktreihen versehen, die beim $\sigma$ auf der Scheibe stärker eingedrückt in seichten Furchen stehen, beim 우 dagegen viel schwächer und an den Seiten nahezu verloschen sind; das I. oder subsuturale Interstitium ist unregelmässig punktiert. Das Propygidium ist in beiden Geschlechtern dicht punktiert, in jedem Punkt ein kurzes, grauweisses Harchen. Das Pygidium ist beim $\sigma$ länger, abor dem After höckerartig vorspringend; beim $ᄋ$ breiter und kürzer, auch etwas flacher, bei beiden dicht nadelrissig und in der vorderen Fälfte kurz gelblich behaart. Bauchringe und Brust sind in der Mitte glänzend, glatt, an den Seiten dicht nadelrissig, erstere ohne die gewöhnliche Querreihe borstentragender 
Punkte. Der Mesosternalfortsatz ist kurz und kräftig, wie bei $R$. histrio, mit der die Art viele habituelle Aehnlichkeit hat; die Vorderschienen sind 3-zähnig, der mittlere und apicale Zahn einander genähert, in beiden Geschlechtern alle Klauen einfach, beim $\sigma^{\prime}$ jedoch an allen Füssen die grossere Klaue länger und dicker als beim 오. Die Fühlerkeule ist in beiden Geschlechtern gleich lang. Die $\sigma$ haben eine Länge von $12 \frac{1}{2}-14$ bei einer Breite von $7-7,1 / 2 \mathrm{~mm}$; die 오 sind meistens etwas grösser und messen $14-16 \mathrm{resp} .8-9 \mathrm{~mm}$.

33. Plusiotis argentoola Bates. $2 \sigma^{\prime}$ von Balzapamba. Bates beschrieb die Art nach einem einzelnen Stitck, das im sthdl. Golumbien nahe der Grenze von Ecuador zwischen Pasto und der pacifischen Kuste gefunden wurde. Eben daher stammt ein Pärchen in meiner Sammlung. Aus dem Dresdener Museum liegt mir ein 우 vor, das Herr Prof. Bässler in Lima kaufte und das angeblich vom Chanchamayo stammt. Wie mir Herr Haensch mitteilt, kam der Kafer des Abends ans Licht geflogen.

34. Chrysophora chrysochlora Latr. In grösserer Anzahl bei Napo an Schilf, einzelne Stücke kamen des Abends nach dem Licht geflogen.

35. Platycoelia humeralis Bates? Ein einzelnes $\sigma$ von Balzapamba.

36. Spodochlamys gigas Murray. 1 or von Balzapamba. Murray hat im Edinburgh New Philosophical Journal, New Series, for April 1857 p. 228 (p. 10 des Separatabdruckes) einen Käfer beschrieben, den er nach dem Habitus - er hat an dem einzigen, noch dazu defekten Exemplar, das ihm vorlag, die Mundteile nicht -untersucht - in die Gattung Leucothyreus neben opacus Perty stellte. Beschreibung und Abbildung dieses Käfers brachten mich auf die Vermutung, dass es sich um eine Art der Gattung Spodochlamys handle und Herr Arrow vom British Museum hat mir nach Untersuchung der Type diese Vermutung bestätigt. Sp. gigas steht der cupveola Bates von Panama-Chiriqui sehr nahe, unterscheidet sich aber leicht durch die Form der Oberlippe, die bei gigas in der Mitte eine zwischen die Oberkiefer vorspringende Spitze trägt, wäh- , rend sie bei cupreola $z w a r$ in der Mitte am längsten ist, von da aber nach den Seiten zu ganz allmälig schmälẹ wird. Ausserdem ist in beiden Geschlechtern bei cupreola an allen Ftissen die grössere Klaue gespalten, bei gigas nur an den Vorder- und Mittelfüssen, während an den Hinterfüssen beide Klauen einfach sind. 
Herr v. Mathan sammelte den Käfer in Anzahl ebenfalls bei Balzapamba (III IV. 94) und bei Chimbo (I. Sem. 92); ein einzelnes $\sigma^{\prime}$ sammelte Herr Rosenberg bei Chimbo im August 97.

Der Leucothyreus purpureosericeus Nonfr. aus Porto viejo, Ecuador, gehorrt als Synonym zu $S p$. gigas Murray, wie ich nach Untersuchung der Type, die mir Herr Nonfried in liebenswürdigster Weise zur Ansicht schickte, feststellen konnte.

37. Bolax Oberthuiri n. sp. Dem $B$. castaneicollis Burm. von Columbien zunächst verwandt, der ganze Körper glänzend kastanienbraun, nur die Deckflügel hell bräunlichgelb (die Nat gewöhnlich etwas dunkler) mit hellgelben Streifen. Das Kopfschild ist kurz trapezförmig, die Seiten beim $\sigma^{\top}$ stärker convergierend als beim 우, mit grossen zusammenfliessenden Punkten dicht bedeckt. Die Stirnnat ist geradlinig, an den Seiten, bes. beim $\&$, leicht kielartig erhaben, die Stirn in der Mitte mit einem kleinen Höcker, dicht und kräftig punktiert, die Punkte bei den Augen vielfach zusammenfliessend und je ein gelbliches Härchen tragend; der Scheitel weitläufiger punktiert, die Punkte an den Seiten ebenfalls Härchen tragend. Der Thorax ist hoch gewölbt, an den Seiten stark erweitert, diese nach hinten stärker gebogen als nach vorn, die spitzwinkligen Vorderecken und stumpfwinkligen Hinterecken in eine Spitze ausgezogen, mit scharf eingeprägter Randfurche und drei schiefen Quereindrücken jederseits, die zuweilen flacher, zuweilen in einzelne Grübchen oder Punkte aufgelöst sind; auch eine mittlere Längsfurche ist vorhanden, aber meist in einzelne Grübchen aufgelöst; die ganze Oberfläche ist mit tiefen Punkten bedeckt, an den Seiten dichter als in der Mitte, sodass hier einzelue glatte Felder sich aus dem Gewirr von Punkten und Furchen resp. Grübchen hervorheben; aus den Punkten entspringen vielfach gelbliche lange Haare, die an ihrer Basis verbreitert sind. Das kleine Schildchen ist dicht punktiert, die Ränder glatt. Die Deckflügel sind hochgewölbt, nach hinten etwas verbreitert, an den Seiten regelmässig gestreift-punktiert, auf der Scheibe sind die Punkte der Punktstreifen quer eingedrikckt und fliessen vielfach zusammen, besonders hinter dem Schildchen, sodass hier die Sculptur undeutlich wird. Von den hellgelben Streifen entsprechen die breiteren, homogenen den primären Rippen; in ihnen lässt sich bei stärkerer Vergrösserung deutlich der für die prim. Rippen charakteristische Tracheenstamm erkennen; nur der helle Streifen, der der ersten prim. Rippe dicht neben der etwas dunkleren Nat entspricht, verschmilzt mit der hellen Farbung, die das ganze erste Interstitium erftillt. Im zweiten Interstitium sehen wir 
unter der Lupe den hellen Streifen sich in einen Doppelstreifen von einzelnen hellen Punkten (Luftbläschen) auflösen, im dritten ist der helle Streifen nur bei der Basis oder bis zur Mitte doppelt.

Alle Streifen gehen nicht bis zum Hinterrand, sondern vereinigen sich hinter dem Apicalbuckel. Die Afterdecke ist dicht nadelrissig und anliegend weiss behaart, ubber dem After ausserdem mit langen rotgelben Haaren besetzt. Die Bauchringe, beim $c^{\nearrow}$ in der Mitte etwas eingezogen, uberall weitläufig grob punktiert und weiss behaart, sind beim. ㅇ stärker gewölbt und nur mit der gewöbnlichen Querreihe von Punkten besetzt, aus denen kurze gelbliche Härchen entspringen. Brust und Huften sind weitläufig punktiert und weiss behaart. Die Vorderschienen sind 3 zähnig, der mittlere und apicale Zahn einander genähert, die Vordertarsen beim $\sigma$ stark verbreitert, in beiden Geschlechtern an allen Füssen die grössere Klaue fein gespalten, beim ơ die innere Klaue der Vorderfüsse viel kleiner und feiner gespalten als beim 오.

O․ L. $13-14$, Br. $6 \%_{2}-7 \mathrm{~mm}$. 우 L. $15-181 / \mathrm{s}$, Br. $8-91 / 2 \mathrm{~mm}$.

Die ersten Stücke erhielt ich von Herrn René Oberthür in Rennes, dem ich diese Art widme; sie tragen die Fundangabe: de Banos à Canelos (M. de Mathan), Sept.-- Octob. 1894. Herr Haensch sammelte sie in grosser Anzahl von Sept. bis Dez. 1900 bei Sta. Inéz, das zwischen Banos und Canelos liegt. Ein einzelnes $ㅇ$ fand Baron bei den Ruinen von Zamora (bei Loja im südl. Ecuador) im October 1888.

38. Geniates Schmidti n. sp. Langgestreckt, abgeflacht, parallelseitig, oben und unten hell scherbengelb, nur das Hinterhaupt, ein kleiner Fleck mitten auf dem Thorax nahe dem Hinterrand, das Schildchen und 3 undeutliche Streifen auf den Deckflügeln sind braunschwarz, die Kniee und die Hinterschienen wie auch die hinteren Tarsen braun. Das Kopfschild ist kurz trapezförmig, die Ecken gerundet, der Rand ringsum fein erhaben und braun gefärbt, die ganze Fläche mit grossen umwallten Punkten bedeckt. Die Stirnnat ist eine gerade braune Linie, in der Mitte etwas eingedrückt, die Stirn ist flach, dicht punktiert, der Scheitel kaum spärlicher. Das Halsschild ist in der Mitte $3 \% \mathrm{~mm}$ lang, $7 \frac{1}{2}$ breit, flach, ringsum fein gerandet, die Seiten etwas nach oben umgebogen, überall dicht punktiert, ebenso das Schildchen. Die flachen, in der Mitte_ganz schwach verbreiterten Deckfltugel zeigen regelmässige Punktreihen, die die leicht erhabenen prim. Rippen begrenzen. Diese prim. Rippen sind alle hellgelb, die Interstitien auf der Scheibe dagegen dicht mit schwarzbraunen Punkten bedeckt, auch der vor- 
springende Schulterbuckel ist schwarzbraun. Der Seitenrand der Deckflügel ist scharf abgesetzt, braun gefärbt und mit, einer Menge feiller Einkerbungen: versehen, an deren Grund kurze rotgelbe, nach oben gerichtete Borsten stehen. Die mittleren und hinteren Schenkel . sind verlängert, sodass das Knie über den Seitenrand der Deckflügel hinausragt, beim Knie etwas nach oben umgebogen und hier auf ihrer oberen Seite mit feinen Leisten versehen. Streicht der Käfer mit diesen Leisten am Knie über die feinen Zähnchen, die zwischen den Kerben am Deckftügelseitenrand stehen blieben, so entsteht ein deutlich hörbares żirpeades Geräusch: Diese Art von Schrillapparat findet sich bei vielen Geniatiden. Die Afterdecke ist kurz dreiseitig, hochgewölbt, ganz verloschen quer punktiert, an der spitze rotgelb behaart. Die Bauchringe sind mit der gewöhnlichen Querreihe. borstentragender Punkte besetzt, glänzend, in der Mitte glatt, an den Seiten seicht punktiert; ebenso ist die hanrlose Brust sculptiert. Die Schenkel und Schienen sind abstehend rotbraun behaart, die Vorderschienen 3-zähnig, der basale Zahn jedoch beim $\sigma$ nur noch ganz schwach angedeutet, an den Hinterschienen der obere Sporn beim $\sigma^{\prime}$ verlängert und nahezu rechtwinklig gelkrummt, fig. 44: Beim $\sigma$ sind an allen Fussen, besonders aber an den vorderen und mittleren die vier ersten Tarsenglieder blattartig verbreitert, an allen Füssen die grössere Klaue gespalten. .

б. L. 19, Br. $9^{1} / 2: \mathrm{mm}$. Ein einzelnes ơ bei Sta. Inéz erbeutet und Herrn E. Schmidt, dem Begleiter des Herrn Haensch gewidmet; die Type befindet sich im Berliner Museum.

Die Orte, von welchen Herr Haensch Ruteliden mitbrachte, lassen sich nach ihrer geographischen Lage in drei Gruppen teilen. Zur ersten rechne ich Balzapamba, 750 -Meter uber dem Meer, und Palmar, $100 \mathrm{~m}$., die an den westlichen Abhängen der Cordilleren resp. in der Ebene vor diesen liegen. Zur zweiten Sta. Inéz, $1250 \mathrm{~m}$, Bannos, $1850 \mathrm{~m}$ und Baiza, $1500 \mathrm{~m}$, die im Hochgebirge oder an seinen östlichen Abhängen in beträchlicher Erhebung über dem Meer liegen. Zur dritten Gruppe rechne ich die am Fuss der ostlichen Abhänge der Cordilleren gelegenen Onte Napo, $440 \mathrm{~m}$, Aguamo, $307 \mathrm{~m}$ und Coca, $260 \mathrm{~m}$.

Von den vorliegenden 38 Arten sind Anomala undulata und marginata sowie Strigoderma sulcipennis uber das ganze warme Amerika, A. testaceipennis von Costa-Rica bis Paraguay verbreitet. Die bei Napo, Aguamo und Coca gemachten Funde gehören alle zu Arten, die in den niedrigen Gebirgslagen am Ostabhang der Cordilleren in Columbien, Ecuador und Peru, an den oberen Nebenflüssen des Amazonas und durch dessen Flusstal bis nach Para und Guay- 
ana verbreitet sind. Viele dieser Arten sind offenbar in Begriff; in den einzelnen Provinzen dieses weiten Verbreitungsgebietes selbstăndige Lokalformen zu bilden, wie z. B. Lagochïle sparsa und Chlorota terminata; auch Rutela lineola gehört zu diesen, doch habe ich, um die Arbeit nicht zu umfangreich werden zu lassen, es unterlassen, die einzelnen Lokalformen dieser weit verbreiteten Art hier $\mathrm{zu}$ besprechen. Wenn andere auf bestimmte Teile dieses Gebietes beschränkt zu sein scheinen, so möchte ich darauf hinweisen, dass es uns hier noch sehr an zuverlissigen Beobachtungen fehlt; grosse Teile dieses Gebietes sind aberhaupt noch gänzlich unerforscht, andererseits baben die Naturforscher, die diese Gegenden bereisten, den Käfern wenig Aufmerksamkeit gewidmet oder, wie z. B. Bates, der 11 Jahre hindurch die Verbreitung der Arten innerhalb des Amazonasgebietes studierte, ihre Beobachtungen nicht veröffentlicht.

Am Westabhang der Cordilleren; bei Balzapamba und Palmar sammelte Herr Haensch 10 Species, von denen sich 7, nemlich Anomala popayana, Lagochile sparsa und chiriquina, Macraspis melanaria, Antichira jodiella, Plusiotis argenteola und Platycoelia humeralis auch weiterhin an der Westseite der Cordilleren bis zur Landenge von Panama vorfinden; 3 andere, Anomala balzapambae, Rutela dimorpha und Spodochlamys gigas sind bis jetzt nur hier gefunden worden.

Dagegen gehören alle im Hochgebirg gesammelten Arten - abgesehen von den weit verbreiteten Anomala testaceipennis und Strigoderma sulcipennis -- zu endemischen Arten, die bisher nur in Ecuador gefunden wurden oder uberhaupt neu sind für die Wissenschaft. Die Lebensbedingungen sind im Hochgebirge offenbar viel verschiedenartiger, die Verbreitungsmöglichkeit der Arten ist eine beschränktere, sodass sich hier leichter lokale Formen ausbilden können, als in der Ebene.

Kurz recapituliert ergiebt sich aus einer Betrachtung der Rutelidenausbeute des Herrn Haensch eine scharfe Trennung der Fauna Ecuador's in ein ostandines, westandines und Hochgebirgs-Gebiet. Jedes dieser Gebiete hat seine eignen Arten, die den beiden anderen Gebieten fehlen. Keine der im ostandinen Gebiet Ecuador's gefundenen Arten ist in diesem Gebiet endemisch; im westandinen sind es nur 3, wäbrend 7 auch weiterhin an der Westküste vorkommen. Im Hochgebirge dagegen ist alles endemisch; hier hat jeder hohe Berg, jedes Tal seine eignen Formen.

Die von Herrn Haensch in Ecuador gesammelten Ruteliden bilden nur einen Bruchteil dessen, was bisher an Ruteliden aus Ecuador beschrieben wurde oder in den Sammlungen noch der Beschrei- 
bung harrt und es war zuerst meine Absicht, eine Uebersicht ther die ganze Rutelidenfauna von Ecuador zu geben. Ich habe aber davon Abstand genommen, weil die Mehrzahl der beschriebenen Arten nur die allgemeine Fundortangabe Ecuador trägt - auch ein Teil der von Blanchard mit der Angabe Nouvelle Grenade bezeichneten Arten stammt aus Ecuador, das eine Zeit lang mit Columbien vereinigt war - und weil durch diese Arten mit ungenauer Herkunft das klare Bild von der geographischen Verbreitung der Arten innerhalb des Landes, die Teilung in eine ostandine, westandine und Hochgebirgsfauna, die sich gerade aus der Haensch'schen Ausbeute mit solcher Klarbeit ergiebt, in seinen Umrissen verwischt worden wäre. Für alle Fragen der Systematik, nicht bloss für das Studium der geographischen Verbreitung der Arten, haben nur Stucke mit genauen und zuverlässigen Fundortangaben Werth; nur eine genaue Fundortangabe setzt uns in den Stand zu ergrinden, welche ausseren Einflusse, Temperatur, Futter u. s. w. auf das Tier eingewirkt haben können um es so zu gestalten, wie wir es vor uns sehen und darum halte ich es fur richtiger, solche Stücke mit ungenauen oder unzuverlässigen Fundortsangaben wenigstens bei faumistischen Arbeiten nicht $\mathrm{zu}$ berücksichtigen. 


\section{Verzelchnis der neu beschriebenen Arten} und Gattungen.

Seite

Lagochile solimoënsis n. sp. Ecuador $\ldots . \quad \ldots \quad+\quad . \quad \therefore 220$.

L. panamensis.n. sp. Chiriqui. . . . . . . . . . 221

L. sparsa n. sp. Columb., Ecuador, Amazonas . . . . . . 222

L. . : subspec. subandina Bolivia, Peru, Ecuador . . . 224

L. " " littoralis Ceara, Bahia, Santos . . . . 225

L. aridicola n. sp. Ecuador, Sta. Inéz . . . . . . . . . 226

L. cachectica n. sp. " " " . . . . . . ... . 227

Pseudomacraspis, gen. nov. Antichiridarum . . . . . . 229

Für Antichira affinis Cast., beryllina Er., Ps. cayennensis

n. sp. Cayenne . . . . . . . . . . . . . 229

und Ps. imitatrix n. sp. Peru . . . . . . . : $\quad \vdots \quad \vdots 29$

Rutela dimorpha n. sp. Ecuador. . . . . . . . . . . 233

Spodochlamys (nec Leucothyreus) gigas Murray . . . . . 234

$=S p$. (nec Leucothyreus) purpureosericeus Nonfr.

Bolax Oberthüri n. sp. Ecuador . . . . . . . . . . . 235

Geniates Schmidii n. sp. Ecuador .. . . . . . . . 236

Stridulationsorgane bei Lagochile, . . . . . . . . . 219

bei Geniates . . . . . . . . . . . . . . . . . . 236 

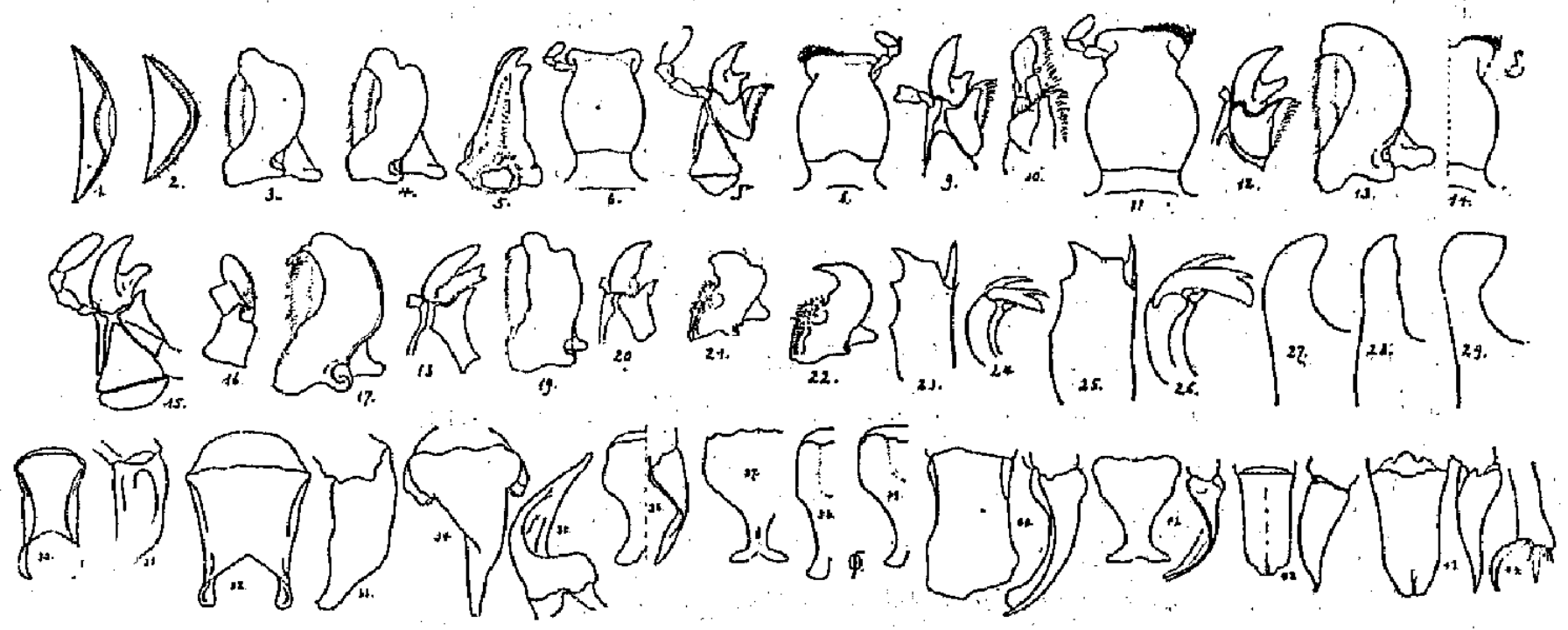

Erklärung der Abbildungen.

Fig. 1. Ventralplatte des Analsegmentes, Lagochile brunnipes Oliv ' $\sigma$ ' 2. Dieselbe beim 우.

"3. Lagochile brunnipes Oliv. R. Oberkiefer des $\sigma$ von der Seite.

"4.

$" 5$.

" 6.

"7.

- 8 .

„9.

" 10 :

" 11 .

" 12.

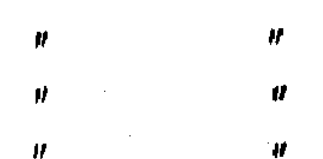

" solimo panamensis "

" " " " " " 우 " vorn."

"Submentum, Mentum u. Unterlippe.

R. Unterkiefer von der Sqite.
sp. Unterlippengerist.

Unterkiefer von der Seite.

$$
\text { "von vorn. }
$$

"13. Lagochile sparsa n. sp. $\sigma$ Balzapamba, R. Oberkiefer.

14.

"15. 16.

"17. 18.

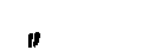

,

Unterlippengerust. Unterkiefer von der Seite und von vorn. subspec. littoralis ơ Bahia. R. Ober. u. Unterkiefer.

"19, 20. " andicola n. sp. $\sigma$. R. Ober- und Unterkiefer.

"21. Macraspis chrysis L. $\sigma^{7}$ Cayenne. R. Oberkiefer.

"22. Pseudomacraspis affinis Cast. $\sigma$ Cayenne. R. Oberkiefer.

"23. 24.

$\sigma$ Surinam. L. Vorderschiene und Vorderklaue.

" $25,26$.

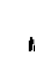

$\sigma$ Rio Javary. L. Vorder-

„27.

" schiene u. Vorderklaue. " $\sigma$ Cayenne. Mesosternalforts. 
Fig.28. Macraspis chrysis L. $\sigma^{\prime}$ Mesosternalfortsatz.

"29. " andicola Burm. $\sigma$ Peru. "

Linke Seiten- und Rückenansicht der Forepsparameren von

"30. 31. Lagochile brannipes Oliv. Cayenne.

"32. 33. L. solimoënsis n. sp. Napo.

"34. 35. L. panamensis n. sp. Chiriqui.

"36. L. sparsa n. sp. Balzapamba.

"37. " " " Columbien.

"38. " " " "subsp. subandina. Mapiri.

"39. " " " littoralis. Bahia.

"40. " chiriquina Bates. Balzapamba.

"41. " andicola n. sp. Sta. Inéz.

"42. Psendomacraspis affinis Cast. Surinam.

"43. " " Rio Javary.

"44. Geniates Schmidti n. sp. ơ" Sta. Inéz. L.. Hinterschiene von innen. 